Daugavpils University, Riga Teacher Training and Educational Management Academy, Latvia

LİGA ROĶE

Riga Teacher Training and Educational Management Academy, Latvia

\title{
ADAPTATION OF RUNCO IDEATIONAL BEHAVIOR SCALE IN LATVIA
}

\begin{abstract}
Runco Ideational Behavior Scale (RIBS) was developed as an alternative instrument to measure creativity in contrast with divergent thinking tests which have only moderate predictive validity. Measure of RIBS is based on the assumption that ideas are the products of original, divergent, and creative thinking behaviour which one can observe and report about his/herself. The aim of the study was to adapt RIBS in Latvia. For the estimation of psychometric properties and constructing validity with confirmatory factor analysis (CFA) two samples were involved initial sample $(N=107)$ and comparison sample $(N=130)$. After evaluating the Latvian version of RIBS, two issues were identified: the first pertains to reversed items which have no sufficient shared variance with the total scale while the second issue points to serious problems of model fit challenging one factor solution of ideational behaviour. The possible reasons of these problems are discussed and further steps for RIBS development are proposed, including a change of response scale in order to test the effect of reversed items, establishing the validity with other instruments and investigating the appropriate number of factors to reveal more valid structure of ideational behaviour.

Similar to the original RIBS the adapted version also has low factorial validity and thus is temporarily recommended only for studies with purpose to develop this instrument.
\end{abstract}

Keywords: confirmatory factor analysis; creative ideation; creativity; reliability; validity

\section{INTRODUCTION}

The theoretical concepts of creativity nowadays are characterized by a great variety and thus - by a lack of one, clear definition of creativity. It is closely bounded to the variety of instruments designed to measure this complex phenomenon. Widely known complex models of creativity have been elaborated by R. Sternberg, T. Amabile, K. Urban, H. Jellen, and M. Csikszentmihalyi.

S. von Stumm, A. Chung and A. Furnham lately proposed a model where creativity is a competence that results from three core elements: creative ability or capacity, creative ideation or thinking disposition and creative achievement (Stumm, Chung, \& Furnham, 2011). Research studies often rely on divergent thinking tests where creativity is interpreted in terms of fluency and originality criteria. At the same time, several researchers (Torrance, Sternberg, etc.) admit, that divergent thinking is a necessary but not sufficient component of creativity. Moreover, as Fiske and Butler (1963) note, it is worth distinguishing between maximum possible creative performance or potential (refers to what an individual can do) and typical performance as individual's behavioural tendency (refers to what an individual will do). Both performances involve divergent thinking, but the second one is determined not only by creative ability but also by its expression in individual's everyday behaviour. Plucker, Runco and Lim (2006) in 
earlier study indicated that divergent thinking was marginally associated with creative ideation which supports the idea about the distinction between maximum and typical performance measures.

In this context generation of creative ideas in everyday life can be attributed to the indicators of typical creative performance. The instrument Runco Ideational Behaviour Scale has been developed with a purpose to measure idea generation - it is a self-report measure for individual's ability to be original, flexible and fluent in ideation - these are the aspects of divergent thinking. The authors of RIBS admit that the theoretical background of the scale is found in P. Guilford's Structure of Intellect Model (1967) and specifically - in the notion that "ideas are a result of original, divergent and creative thinking processes". Furthermore, they defined creative ideation as actual behaviours which reflect "the individual's use of, appreciation of and skill with ideas". They intended RIBS as an alternative method for creativity assessment. Their main assumption was that "ideas can be considered as the products of original, divergent and even creative thinking" (Runco, Plucker, \& Lim, 2000-2001, 394). From this perspective creative ideas can be viewed as a characteristic which is normally distributed in population or as everyday creativity (Runco, \& Richards, 1998). A. Runco proposes that the measure of ideation can be used as an adequate creativity criteria since it presupposes both idea generation, attribution of value to it and certain skills necessary for it.

A. Runco has pointed to the weaknesses of "product approach" in creativity research, which, although widely used, has limitations: in using it for research of children and nonprofessionals, it does not explain the processes which are at the basis of creative product creation, the discriminant validity of judges' rating of creativity is debatable; besides, the assessment of creative product is time-consuming and prone to mistakes in evaluation process (Batey, ChamorroPremuzic, \& Furnham, 2009).

In order to measure ideational behaviour, A. Runco and J. Plucker developed a set of 100 items, and afterwards reduced it to 23 items which reflect ideation principles. The statements were assessed in 5-point scale, where 1 point means - never, and 5 points - very often. This version of RIBS contained 5 subscales (Plucker, Runco, \& Lim, 2000-2001).

In 2009 A. Runco modified RIBS by adding statements to amount to 49 and changing the description of evaluation scale (answers in the form of $0-4$ where they were described as the frequency of behaviour in certain time periods: 0 - never, 1 - once a year, 2 - every month, 3 every week, 4 - every day), but preserving the one-factor structure of the scale.

Some researchers point out to the weaknesses of RIBS: self-report character as well as limited possibilities to apply it to all age groups, for example, children (Plucker, \& Makel, 2010). Nevertheless, it was considered to be useful to adapt and reveal the possibilities of RIBS to measure ideational behaviour as one of the creativity aspects.

\section{THE AIM OF THE STUDY}

To adapt the Latvian version of RIBS-09.

\section{MATERIALS AND METHODS}

\section{Participants}

The initial sample of adaptation study of Latvian RIBS-09 consisted of 107 adults (102 women, 5 men), mostly psychology students of master programs, and teachers, aged between 24 and 68 years $(M=41.6 ; S D=10.8)$. The second sample of the adaptation study (comparison sample) consisted of 130 adults (74 women, 56 men) mostly students from various fields, aged between 18 and 43 years $(\mathrm{M}=21.7, \mathrm{SD}=3.7)$. 


\section{Procedure}

The adaptation process included receiving the permission from the author of RIBS-09 to translate the scale into Latvian. A team of two psychologists (both fluent in both Latvian and English, with a Master's degree in Psychology, specialized in Psychology of Creativity) translated the instruction and items of 49-item RIBS from English to Latvian. They tried to avoid poor readability and lack of naturalness, well-known problems of close translations (Harkness, 2003). The two translated versions were compared, the differences were discussed and the most appropriate translation was determined. A pilot study $(\mathrm{N}=3)$ was carried out in order to test the respondents' perception of testing form design, instructions and items.

The Latvian version of RIBS was administered frontally, in groups of 25-20 people. After the first testing round with the initial sample $(\mathrm{N}=107)$ statistics and psychometric properties were calculated and unsatisfactory items were analysed. For the comparison sample $(\mathrm{N}=130)$ modified translated version was administrated and the obtained data were used for the calculation of statistics and psychometric properties. The data from the comparison sample were also used to conduct conditional exploratory factor analysis (EFA) for obtaining the results of salient loadings and proportion of explained variance by items. After EFA the confirmatory factor analysis (CFA) was made putting emphasis on examining proposed model fit.

Descriptive statistics and reliability was calculated with $\mathrm{R}$ statistics ( $\mathrm{R}$ Development Core Team, 2011) using package psych (Revelle, 2009-2010), while factor analytical research was conducted with Mplus software (Muthén \& Muthén, 1998-2010).

\section{RESULTS}

Basic psychometric properties for the items of RIBS were calculated for both the initial and comparison samples and are summarized in appendix A of this paper. The summary includes descriptive statistics and item correlation with the scale if an item is dropped. Such correlations provide information about the degree to which a specific item is related to the whole scale and are interpretable together with the scale internal consistency, i. e., coefficient of Cronbach's alpha $(\alpha)$ (Cronbach, 1951). Regardless of consistent use of $\alpha$ nowadays, this coefficient is reported as not recommended by researchers (Zinbarg et al., 2005; Sijtsma, 2008), because the calculations of it assume that items measure the construct in equivalent degree and have no correlated measurement errors which is not true in most cases (Raykov \& Marcoulides, 2011). An alternative way to evaluate the internal consistency is to use the factor analysis approach decomposing the variance of score into four parts: general factor, specific factors, unique of each item and random error, and then exploiting these parts for further calculation estimating coefficient of Omega total $\left(\omega_{t}\right)$ which has stronger theoretical and empirical arguments (Revelle \& Zinbarg, 2009). Thus both coefficient of Cronbach's alpha and Omega total are reported in Table 1 along with the descriptive statistics of the scale.

The results of item analysis from the first, i. e., initial sample, provided in appendix A, suggest that five items (RA6, RA23, RA28, RA35 and RA38) show extremely low correlations with the total scale. All these items are reversed comparing to other items, therefore two hypotheses were brought forward. The first hypothesis assumes that these items do not share sufficient common variance with the scale due to unsuccessful adaptation. The second hypothesis assumes that the problem is due to the nature of reversed items as they are only 6 toward 43 positively defined items and thus do not share sufficient common variances because of method effect (Podsakoff et al., 2003). If the second hypothesis is true then it could lead to the conclusion that the explained variance of the scale is significantly influenced by variance due to item 
statistical distributions (Bernstein et al., 1988) and thereby threatens the conception of one factor solution of RIBS. Considering these two hypotheses, changes in the translations of five reversed items were made and eliminated the possible reasons of bad item reactions. One of these items was re-reversed retaining the same content in order to test the second hypothesis. Considering the threat of dissimilar samples, information about changed items comparing correlations in the initial and comparison samples could be extracted from the table in appendix A. Results suggest that all but one re-reversed item continues to be responded to in unexpected manner showing critically low correlations with the total scale (-0.09 to 0.02$)$. This strengthens the assumptions of the second hypothesis, thus a further inspection of scale reliability and factor structure is carried out. The translation of five more items was slightly modified due to cultural differences between USA and Latvia (A28), in order to give more accurate psychological meaning to the translated item in the context of the measured construct (A8, A20, A23), or to avoid social desirability in responses (A19).

Table 1 provides psychometric properties of the total scale for the initial sample (RIBS I), for the comparison sample (RIBS C) and for the comparison sample if reversed items are eliminated (RIBS Rev). The estimation of scale reliability gives evidence that in both samples internal consistency of RIBS is very high, showing better results for the initial sample. Although the coefficient of Alpha is the highest, in the comparison sample for revised RIBS referring to previous discussion on reliability, coefficient of Omega total should guide the interpretation, although differences in our case are negligible.

Table 1. Descriptive statistics and reliability of RIBS

\begin{tabular}{ccccccccc}
\hline Version & $\mathbf{n}$ & $\begin{array}{c}\text { std. alpha } \\
\boldsymbol{\alpha}\end{array}$ & $\begin{array}{c}\text { Omega total } \\
\left(\boldsymbol{(}_{\mathbf{t}}\right)\end{array}$ & $\begin{array}{c}\text { average } \\
\mathbf{r}\end{array}$ & mean & sd & Skewness & Kurtosis \\
\hline RIBS I & 83 & .908 & .923 & .167 & 2.17 & .457 & .17 & -.76 \\
RIBS C & 130 & .900 & .911 & .155 & 2.08 & .474 & .08 & .25 \\
RIBS Rev. & 130 & .912 & .913 & .187 & 2.04 & .511 & .01 & .01 \\
\hline
\end{tabular}

RIBS I - n-sample size, std. alpha - The standardized alpha, average $\mathrm{r}$ - The average interitem correlation, sd standard deviation

Exploratory factor analysis (EFA) is an appropriate way for obtaining the evidence of structure of construct and reliability because it allows to evaluate, to what degree expected indicators load onto a certain factor (or factors) (Tucker \& MacCallum, 1997). EFA and also confirmatory factor analysis (CFA) use a common factor model (Thurstone, 1947) in which indicators as observed variables are a linear function of the common factor (or factors) and one unique factor. Thus the theoretical construct or ideational behaviour in our case is regarded as a cause of fluctuations in items. Traditional factor extraction methods, such as maximum likelihood and others which assume that data are continuous, usually perform badly for items on Likert scales (Bernstein \& Teng, 1989). The main reasons that the traditional extraction should not be used concern statistical distributions of items, which being on Likert scale are prone to make artificial correlations due to distributional similarity, even when all items measure only one latent variable (Nunnaly \& Bernstein, 1994). The effect could be reduced using the matrix of polychoric correlations instead of matrix of Pearson correlations (Panter et al., 1997). One of the good performing extraction methods where the described problem is resolved, is the robust weighted 
least square (WLSMV) extraction method. WLSMV performs adequately also with small sample sizes ranging from 100-1000 (Flora \& Curran, 2004) and is appropriate for conducting both EFA and CFA using Mplus software (Muthén \& Muthén, 1998-2010). Standardized factor loadings from EFA with WLSMV making the constraint for one factor solution are provided in Table 2, accounting for $22.5 \%$ variance in indicators. Examining results of factor analysis the same four reversed items (RA6, RA23, RA28, RA38) show extremely low loadings and one straight item has the loading below .3, what could be considered as a boarder for salient loadings (Brown, 2006).

Table 2. Factor loadings with WLSMV factor extraction method for RIBS

\begin{tabular}{l|ccccccccccccccccc}
\hline Item & $A 1$ & $A 2$ & $A 3$ & $A 4$ & $A 5$ & $R A 6$ & $A 7$ & $A 8$ & $A 9$ & $A 10$ & $A 11$ & $A 12$ & $A 13$ & $A 14$ & $A 15$ & $A 16$ & $A 17$ \\
EFA $_{\text {Load. }}$ & .30 & .18 & .34 & .44 & .46 & .06 & .54 & .48 & .41 & .49 & .60 & .61 & .50 & .59 & .48 & .41 & .32 \\
CFA $_{\text {Load. }}$ & .40 & .23 & .44 & .57 & .60 & .08 & .71 & .63 & .53 & .64 & .78 & .80 & .66 & .77 & .62 & .54 & .42 \\
CFA $_{\text {S.E. }}$ & .10 & .11 & .09 & .09 & .08 & .10 & .08 & .09 & .09 & .09 & .08 & .08 & .08 & .08 & .09 & .09 & .10 \\
CFA $_{\text {Est./S.E. }}$ & 4,1 & 2,1 & 4,9 & 6,2 & 7,7 & 0,8 & 9,0 & 6,9 & 6,1 & 7,1 & 10,0 & 10,2 & 8,5 & 10,3 & 6,9 & 6,2 & 4,2 \\
CFA $_{\text {2-sig. }}$ & .00 & .03 & .00 & .00 & .00 & .43 & .00 & .00 & .00 & .00 & .00 & .00 & .00 & .00 & .00 & .00 & .00 \\
\hline
\end{tabular}

\begin{tabular}{l|rrrrrrrrrrrrrrrr}
\hline Item & $A 18$ & $A 19$ & $A 20$ & $A 21$ & $A 22$ & $R A 23$ & $A 24$ & $A 25$ & $A 26$ & $A 27$ & $R A 28$ & $A 29$ & $A 30$ & $A 31$ & $A 32$ & $A 33$ \\
EFA $_{\text {Load. }}$ & .56 & .43 & .57 & .54 & .38 & .09 & .42 & .44 & .51 & .59 & .03 & .34 & .62 & .70 & .77 & .46 \\
CFA $_{\text {Load. }}$ & .72 & .56 & .74 & .70 & .50 & .12 & .55 & .58 & .66 & .77 & .04 & .44 & .81 & .91 & 1.00 & .60 \\
CFA $_{\text {S.E. }}$ & .08 & .09 & .08 & .08 & .09 & .10 & .08 & .08 & .09 & .07 & .11 & .10 & .07 & .07 & .00 & .09 \\
CFA $_{\text {Est./S.E.. }}$ & 9.6 & 6.4 & 9.8 & 8.8 & 5.3 & 1.2 & 6.9 & 7.5 & 7.1 & 11.3 & 0.4 & 4.6 & 11.0 & 13.8 & 999 & 6.6 \\
CFA $_{\text {2-sig. }}$ & .00 & .00 & .00 & .00 & .00 & .22 & .00 & .00 & .00 & .00 & .70 & .00 & .00 & .00 & 999 & .00 \\
\hline
\end{tabular}

\begin{tabular}{l|rrrrrrrrrrrrrrrr}
\hline Item & $A 34$ & $A 35$ & $A 36$ & $A 37$ & $R A 38$ & $A 39$ & $A 40$ & $A 41$ & $A 42$ & $A 43$ & $A 44$ & $A 45$ & $A 46$ & $A 47$ & $A 48$ & $A 49$ \\
EFA $_{\text {Load. }}$ & .34 & .45 & .46 & .51 & .01 & .62 & .45 & .51 & .71 & .60 & .33 & .43 & .52 & .39 & .43 & .42 \\
CFA $_{\text {Load. }}$ & .44 & .59 & .59 & .67 & .01 & .80 & .58 & .67 & .92 & .77 & .42 & .56 & .67 & .51 & .56 & .54 \\
CFA $_{\text {S.E. }}$ & .09 & .08 & .08 & .08 & .11 & .07 & .09 & .09 & .07 & .08 & .09 & .09 & .08 & .09 & .10 & .09 \\
CFA $_{\text {Est./S.E.. }}$ & 4.9 & 7.2 & 7.6 & 8.9 & 0.1 & 12.3 & 6.7 & 7.6 & 13.9 & 9.6 & 4.7 & 6.6 & 8.4 & 5.5 & 5.6 & 6.0 \\
CFA $_{\text {2-sig. }}$ & .00 & .00 & .00 & .00 & .93 & .00 & .00 & .00 & .00 & .00 & .00 & .00 & .00 & .00 & .00 & .00 \\
\hline
\end{tabular}

Factor analysis is made with the comparison sample $(\mathrm{N}=130)$; $\mathrm{EFA}_{\mathrm{Load}}$ - standardized loadings from EFA; $\mathrm{CFA}_{\text {Load. }}$ - unstandardized loadings from CFA; $\mathrm{CFA}_{\text {S.E. }}$ - Standard error of estimated loadings; $\mathrm{CFA}_{\text {Est./S.E. }}-$ Estimated loading divided by standard error ( $\mathrm{z}$ value); $\mathrm{CFA}_{2 \text {-sig }}$ - significance of factor loading onto factor.

Although basic psychometrics (e.g., item characteristics, scale reliability) and exploratory factor analysis of RIBS, if bad items are removed, claim for acceptance of RIBS as an instrument due to good internal consistency, investigation of construct validity is still required. Appropriate framework for the investigation of construct validity of an instrument is confirmatory factor analysis (CFA) where one could test theoretical model with empirical data. CFA framework in contrast to EFA allows making restrictions required to prove theoretical connections between the construct and observed variables as well as allows to evaluate, how reasonable the explanation of correlations between the observed variables in a real data set by the theoretical measurement model is. An evaluation of CFA is mainly is based on various fit indices which could be classified under three broad categories: absolute fit, fit adjusting for model parsimony and comparative 
incremental fit (Brown, 2006). As each category represents different information about model fit, it is advised to report at least one index from each category as well as localized areas of ill fit, interpretability and size of parameter estimates (Brown, 2006). In the current research a selection of fit indices from each category, i. e., SRMR, CFI, TLI and RMSEA (Steiger \& Lind, 1980) is based on the findings from data simulations by $\mathrm{Hu}$ and Bentler (1999).

Standardized root mean square residual (SRMR) belongs to the absolute fit category and characterizes average discrepancy between the input correlation and model predicted correlation matrix, but Ching-Yun Yu has shown that SRMR does not perform adequately with categorical variables (Yu, 2002). An alternative way for this index is weighted root mean square residual (WRMR) which estimates a discrepancy between the sample and model statistics using probit thresholds, regression coefficients, and residual correlations showing evidence of model fit if below .9 (Muthén \& Muthén, 2002). Comparative fit index (CFI) and Tucker-Lewis index (TLI) belong to the comparative incremental fit category and evaluate the model under investigation in relation to a more restricted model, usually the model in which the covariance among all input indicators is fixed to zero. The indices of CFI and TLI close to .95 or above are considered as acceptable model fit (Hu \& Bentler, 1999). Root mean square approximation (RMSEA) is relevant to fit adjusting for model parsimony category being sensitive to the complexity of the model and assess, how reasonably well the model fits in the population. RMSEA values .05 and below are considered as good model fit and values in range of .05 to .08 - as adequate fit, but values greater than .1 indicate serious problems in the model fit. Along with the values of RMSEA closeness of model fit (Browne \& Cudek, 1993), i. e., probability that RMSEA is less than or equal to .05 should be reported.

CFA was made for two models: 1) RIBS and 2) RIBS without reversed items, setting fixed value 1 for item A32 (I have ideas about a new invention) in the case of both models because it represents most salient loading in EFA (see Table 2) and has more general content of ideational behaviour comparing to other salient loadings. Table 3 summarizes model fit indices for RIBS and for RIBS without reversed items. None of fit indices for both models gives evidence for acceptable model fit except RMSEA value, what could be regarded as a cue for adequate fit. Investigating modification indices also doesn't support proposed models indicating too many statistical significant modification indices (borderline rounded to 4) - 36 residual covariances and 72 regression coefficients for RIBS, but 38 residual covariances and 76 regression coefficients for RIBS without reversed items. Thus, if all items of RIBS are relevant to the construct of ideational behaviour then CFA does not confirm the notation that ideational behaviour is uni-dimensional.

Table 3. Model fit indices for RIBS and RIBS without reversed items

\begin{tabular}{lcccccccc}
\hline Model & Df & $\boldsymbol{\chi}^{2}$ & P- $\boldsymbol{\chi}^{2}$ & WRMR & TLI & CFI & RMSEA & P-RMSEA \\
\hline RIBS & 1127 & 1713.63 & .000 & 1.36 & .737 & .748 & $.063(.075-.069)$ & .000 \\
RIBS Rev. & 945 & 1495.16 & .000 & 1.35 & .756 & .767 & $.067(.60-.073)$ & .000 \\
\hline
\end{tabular}

CFA is made with the comparison sample ( $n=130)$; RIBS - model with all items intended for RIBS; RIBS $_{\text {Rev }}$ - model without reversed items; Df - degrees of freedom; $\chi^{2}$ - Chi square value, P- $\chi^{2}$ - probability based on $\chi^{2}$ statistics that model implied correlations don't differ from input correlations; WRMR - weighted root mean residual; TLI - Tucker Lewis Index, CFI - Comparative Fit Index; RMSEA - Root mean square error approximation; P-RMSEA - closeness of model fit. 
The study concludes that the adapted version of RIBS does not fit to one factor model, moreover it has serious problems with reversed items. One possible reason why reversed items do not work properly could be associated with the specific scale which is used to obtain item responses. This scale in contrast to the usual Likert's scale uses responses referring to real frequencies, i. e., never, once a year, once each month, once each week and every day. Although magnitudes of intervals of traditional Likert's scale are unknown it seems more complicated to define the midpoint for this scale and reverse the responses. If this explanation is true then the use of the traditional Likert's scale (e. g., never, rare, sometimes, often, always) could resolve this problem and give a little, but not satisfactory support for uni-dimensional construct of RIBS because the model in which the reversed items were eliminated also did not show acceptable fit. However if the problem of the reversed items is not resolved with the change of response scale, there is a possibility that positively defined items share great proportion of variance explained by their distributional similarity.

\section{CONCLUSIONS}

The Latvian version of RIBS has high internal consistency. Five items demanded correction in the translation due to extremely low correlations with the total scale, nevertheless, they still showed low discriminant capacity. The results from confirmatory factor analysis challenge the point of view that ideational behaviour is a uni-dimensional construct. These findings concord with previous research where authors (Runco et al., 2001) revealed that twofactor solution of RIBS has better model fit indices, but one-factor solution should be preferred due to a lack of theoretical confirmation for two-factor model (see also Stumm et al., 2011). As CFA of the adapted Latvian version of RIBS also casts doubt on one-factor solution, a search for more appropriate factor solution or selection of suitable items should be the next step in the development of RIBS. This study also demonstrates that the reversed items are irrelevant to the total scale of RIBS, demanding further studies to investigate the effect of response scales and validity relating to other instruments as evidence for refusing hypothesis that the scale variance is strongly influenced by item distributional similarity in contradiction to substantive (contentbased) similarity. Thus the adapted Latvian version of RIBS should be considered as developed version for research purposes while the true reasons of ill model fit are still to be found.

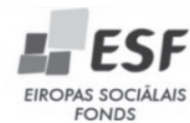

FONDS

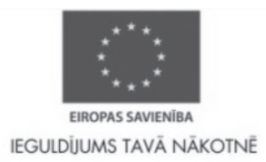

IEGULDUUUMS TAVĀ NÄKOTNË

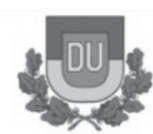

This work has been supported by the European Social Fund within the Project "Support for the implementation of doctoral studies at Daugavpils University" Agreement Nr. 2009/0140/1DP/1.1.2.1.2/09/IPIA/VIAA/015

\section{REFERENCES}

Batey, M., Chamorro-Premuzic, T. \& Furnham, A. (2009). Intelligence and personality as predictors of divergent thinking: the role of general, fluid and crystallised intelligence. Thinking Skills and Creativity, 4(1), 60-69.

Bernstein, I. H., Garbin, C., \& Teng, G. (1988). Applied multivariate analysis. New York: Springer-Verlag.

Bernstein, I. H. \& Teng, G. (1989). Factoring items and factoring scales are different: Spurious evidence for multidimensionality due to item categorization. Psychological Bulletin, 105, 467-477. 
Brown, T. A. (2006). Confirmatory factor analysis for applied research. London: The Guilford Press.

Browne, M. W. \& Cudek, R. (1993). Alternate ways of assessing model fit. In K.A.Bollen. \& J. S.Long (Eds.), Testing structural equation models (pp.136-162). Newbury Park, CA: Sage.

Cronbach, L. J. (1951). Coefficient Alpha and the internal structure of a test. Psychometrika, 16, 297-334.

Fiske, D. W. \& Butler, J. M. (1963). The experimental conditions for measuring individual differences. Educational and Psychological Measurement, 23, 249-266.

Flora, D. B. \& Curran, P. J. (2004). An empirical evaluation of alternative methods of estimation for confirmatory factor analysis with ordinal data. Psychological Methods, 9, 466-491.

Harkness, J. A. (2003). Questionnaire translation. In J. A. Harkness, F.van de Vijver, \& P. Ph. Mohler (Eds.), Cross-cultural survey methods (pp.35-56). New Jersey: Hoboken.

Hu, L. \& Bentler, P. M. (1999). Cutoff criteria for fit indexes in covariance structure analysis: Conventional criteria versus new alternatives. Structural Equation Modeling, 6, 1-55.

Muthén, L. K. \& Muthén, B. O. (1998-2010). Mplus user's guide, $6^{\text {th }}$ Edition. Los Angeles, CA: Muthén \& Muthén.

Muthén, L. K. \& Muthén, B. O. (2002). Mplus, $2^{\text {nd }}$ Edition. Los Angeles, CA: Muthen \& Muthen.

Nunnaly, J. \& Bernstein, I. (1994). Psychometric theory. New York: McGraw-Hill.

Panter, A. T., Swygert, K. A., Dahlstrom, W. G. \& Tanaka, J. S. (1997). Factor analytic approaches to personality item-level data. Journal of Personality Assessment, 68, 561-589.

Plucker, J. A., Makel, M. C. (2010). Assessment of creativity. In J. C. Kaufman \& R J. Sternberg (Eds.), The Cambridge handbook of creativity (pp.48-73).

Plucker, J. A., Runco, M. A. \& Lim, W. (2006). Predicting ideational behavior from divergent thinking and discretionary time on task. Creativity Research Journal, 18(1), 55-63.

Podsakoff, P. M., MacKenzie, S. B., Lee, J. Y. \& Podsakoff, N. P. (2003). Common method biases in behavioral research: A critical review of the literature and recommended remedies. Journal of Applied Psychology, 88, 879-903.

R Development Core Team (2011). $R$ : A language and environment for statistical computing. $R$ foundation for statistical computing. Vienna, Austria. Retrieved December 20, 2011, from http://www.R-project. org/.

Raykov, T. \& Marcoulides, G. A. (2011). Introduction to psychometric theory. New York: Routledge Taylor \& Francis Group.

Revelle, W. \& Zinbarg, R. E. (2009). Coefficients Alpha, Beta, Omega and the glb: Comments on Sijtsma. Psychometrika, 74(1), 145-154.

Revelle, W. (2009-2010). Psych: procedures for personality and psychological research. R package version 1.092. Retrieved December 20, 2011, from http://personality-project.org/.

Runco, M. A. \& Richards, R. (1998). Eminent creativity, everyday creativity, and health. Greenwich, CT: Ablex.

Runco, M. A., Plucker, J. A. \& Lim, W. (2000-2001). Development and psychometric integrity of a measure of ideational behavior. Creativity Research Journal, 13(3\&4), 393-400.

Sijtsma, K. (2008). On the use, the misuse, and the very limited usefulness of Cronbach's alpha. Psychometrika, 74(1), 107-120.

Steiger, J. H. \& Lind, J. M. (1980). Statistically based tests for the number of common factors. Paper presented at the meeting of the Psychometric Society, Iowa City, IA. 
Stumm, S., Chung, A. \& Furnham A. (2011). Creative ability, creative ideation and latent classes of creative achievement: What is the role of personality? Psychology of Aesthetics, Creativity and the Arts, 5(2), $107-114$.

Thurstone, L. L. (1947). Multiple-factor analysis. Chicago: University of Chicago Press.

Tucker, L. R. \& MacCallum, R. C. (1997). Exploratory factor analysis. Unpublished manuscript.

Yu, C. Y. (2002). Evaluating cutoff criteria of model fit indices for latent variable models with binary and continuous outcomes. Submitted doctoral dissertation, University of California, Los Angeles.

Zinbarg, R. E., Revelle, W., Yovel, I. \& Li, W. (2005). Cronbach's $\alpha$, Revelle's $\beta$, and McDonald's $\omega_{\mathrm{H}}$ : Their relations with each other and two alternative conceptualizations of reliability. Psychometrika, 70(1), $123-133$.

Phd student MA. Emīls Kālis

Daugavpils University

Riga Teacher Training and Educational Management Academy, Scientific Research Institute of Pedagogy and Psychology

Address: Blaumaņa 21-8, Riga, LV-1011, Latvia

Phone: 26372915

E-mail: emils.kalis@gmail.com

Researcher MA. Līga Rok̦e

Riga Teacher Training and Educational Management Academy

Scientific Research Institute of Pedagogy and Psychology

Address: Tallinas 45-15, Riga, LV-1012, Latvia

Phone: 26315685

E-mail: liga.roke@rpiva.lv 
Appendix A. Psychometric properties of the items of Latvian RIBS

\begin{tabular}{|c|c|c|c|c|c|c|c|c|c|c|c|c|}
\hline Item & \multicolumn{2}{|c|}{$\mathbf{N}$} & \multicolumn{2}{|c|}{ r.drop } & \multicolumn{2}{|c|}{ mean } & \multicolumn{2}{|c|}{ Skewness } & \multicolumn{2}{|c|}{ Kurtosis } & \multicolumn{2}{|c|}{ sd } \\
\hline & I & II & I & II & I & II & I & II & I & II & I & II \\
\hline A1 & 104 & 137 & 0.24 & 0.28 & 2.8 & 2.6 & -0.65 & -0.58 & -0.05 & -0.55 & 1.0 & 1.2 \\
\hline A2 & 105 & 137 & 0.24 & 0.17 & 1.5 & 1.5 & 1.05 & 0.86 & 1.12 & 0.98 & 0.8 & 0.9 \\
\hline A3 & 106 & 136 & 0.43 & 0.30 & 2.6 & 2.7 & -0.66 & -0.69 & 0.34 & 0.36 & 1.0 & 1.0 \\
\hline A4 & 106 & 137 & 0.37 & 0.39 & 2.1 & 1.7 & 0.21 & 0.33 & -0.78 & -0.38 & 1.1 & 1.0 \\
\hline A5 & 107 & 137 & 0.50 & 0.36 & 1.1 & 1.4 & 0.74 & 0.50 & -0.15 & -0.51 & 1.1 & 1.2 \\
\hline A7 & 105 & 136 & 0.44 & 0.45 & 2.8 & 2.4 & -0.21 & -0.35 & -0.76 & -0.01 & 1.0 & 1.0 \\
\hline A8 & 106 & 137 & 0.38 & 0.34 & 3.3 & 3.1 & -0.91 & -1.01 & 0.18 & 0.75 & 0.8 & 0.9 \\
\hline A9 & 107 & 137 & 0.40 & 0.32 & 2.9 & 2.7 & -0.95 & -0.63 & 0.26 & -0.32 & 1.1 & 1.1 \\
\hline A10 & 105 & 137 & 0.49 & 0.42 & 2.3 & 2.4 & -0.25 & -0.09 & -0.55 & -0.69 & 1.2 & 1.1 \\
\hline A11 & 107 & 137 & 0.58 & 0.49 & 3.0 & 2.7 & -0.49 & -0.37 & -0.24 & -0.05 & 0.9 & 1.0 \\
\hline A12 & 107 & 136 & 0.44 & 0.53 & 2.7 & 2.7 & -0.38 & -0.26 & -0.88 & -0.95 & 1.2 & 1.0 \\
\hline A13 & 106 & 137 & 0.42 & 0.45 & 1.8 & 1.8 & 0.61 & 0.41 & -0.24 & -0.53 & 1.1 & 1.1 \\
\hline A14 & 107 & 137 & 0.50 & 0.52 & 2.8 & 2.7 & -0.26 & -0.20 & -0.49 & -0.45 & 0.9 & 0.9 \\
\hline A15 & 107 & 137 & 0.61 & 0.39 & 2.1 & 2.1 & 0.08 & -0.11 & -0.90 & -0.70 & 1.2 & 1.1 \\
\hline A16 & 107 & 136 & 0.25 & 0.40 & 1.9 & 1.9 & 0.44 & 0.19 & -0.51 & -0.36 & 2.2 & 1.0 \\
\hline A17 & 107 & 137 & 0.41 & 0.29 & 2.0 & 1.9 & 0.08 & 0.26 & -0.56 & -0.77 & 1.1 & 1.2 \\
\hline A18 & 107 & 137 & 0.42 & 0.51 & 1.5 & 1.7 & 0.51 & 0.20 & -0.53 & -0.94 & 1.2 & 1.2 \\
\hline A19 & 105 & 137 & 0.36 & 0.37 & 2.2 & 2.2 & -0.05 & -0.10 & -1.00 & -0.88 & 1.2 & 1.2 \\
\hline A20 & 106 & 136 & 0.47 & 0.49 & 2.9 & 2.7 & -0.49 & -0.18 & -0.37 & -0.59 & 0.9 & 0.9 \\
\hline A21 & 102 & 137 & 0.53 & 0.47 & 1.9 & 1.8 & 0.09 & 0.07 & -0.92 & -0.70 & 1.2 & 1.1 \\
\hline A22 & 107 & 137 & 0.27 & 0.36 & 2.4 & 1.8 & -0.09 & 0.21 & -0.69 & -0.67 & 1.1 & 1.2 \\
\hline A24 & 107 & 137 & 0.57 & 0.37 & 2.4 & 2.3 & -0.02 & -0.30 & -0.97 & -0.68 & 1.1 & 1.2 \\
\hline A25 & 107 & 137 & 0.53 & 0.40 & 2.6 & 2.3 & -0.57 & -0.23 & -0.54 & -0.94 & 1.2 & 1.3 \\
\hline A26 & 107 & 137 & 0.52 & 0.43 & 2.4 & 2.3 & 0.14 & -0.23 & -0.53 & 0.07 & 0.9 & 0.9 \\
\hline A27 & 106 & 137 & 0.51 & 0.52 & 2.4 & 2.2 & 0.03 & 0.31 & -0.29 & -0.17 & 1.0 & 0.9 \\
\hline A 29 & 106 & 137 & 0.25 & 0.27 & 2.0 & 2.5 & 0.10 & -0.26 & -0.99 & -1.07 & 1.2 & 1.3 \\
\hline A 30 & 106 & 137 & 0.62 & 0.52 & 2.4 & 2.3 & 0.15 & -0.06 & -0.52 & -0.21 & 0.8 & 0.9 \\
\hline A31 & 106 & 137 & 0.31 & 0.54 & 1.3 & 1.5 & 0.70 & 0.49 & 0.07 & -0.45 & 1.1 & 1.2 \\
\hline A32 & 106 & 137 & 0.46 & 0.55 & 0.9 & 1.2 & 1.19 & 1.00 & 2.28 & 0.76 & 0.9 & 1.0 \\
\hline A33 & 106 & 137 & 0.41 & 0.39 & 1.7 & 1.3 & 0.30 & 0.76 & -0.66 & -0.06 & 1.2 & 1.1 \\
\hline A34 & 107 & 137 & 0.34 & 0.29 & 1.6 & 1.6 & 0.31 & 0.57 & -0.76 & -0.12 & 1.1 & 1.1 \\
\hline A36 & 104 & 137 & 0.40 & 0.39 & 2.0 & 1.9 & 0.05 & 0.05 & -0.55 & -0.54 & 1.1 & 1.1 \\
\hline A37 & 107 & 137 & 0.55 & 0.42 & 2.2 & 2.1 & 0.20 & 0.11 & -0.90 & -0.19 & 1.0 & 0.9 \\
\hline A39 & 105 & 137 & 0.31 & 0.45 & 1.1 & 1.5 & 0.27 & 0.41 & -0.43 & -0.16 & 0.8 & 1.0 \\
\hline A 40 & 105 & 137 & 0.41 & 0.43 & 2.3 & 2 & -0.05 & 0.15 & -1.02 & -0.73 & 1.2 & 1.1 \\
\hline A41 & 107 & 137 & 0.41 & 0. & 1. & 1.8 & 0.82 & 0.31 & 0.18 & -0.6 & 1.1 & 1.2 \\
\hline A42 & 106 & 137 & 0.50 & 0.4 & 1.0 & 1.2 & 1.03 & 0.80 & 1.55 & 0.48 & 0.9 & 1.0 \\
\hline A43 & 107 & 137 & 0.63 & 0.51 & 2.4 & 2.1 & -0.14 & 0.05 & -0.97 & -0.61 & 1.2 & 1.1 \\
\hline A44 & 106 & 137 & 0.55 & 0.32 & 1.9 & 2 & 0.18 & -0.05 & -0.86 & -0.82 & 1.1 & 1.2 \\
\hline A45 & 107 & 137 & 0.52 & 0.41 & 2.8 & 2.5 & -0.58 & -0.18 & -0.50 & -0.97 & 1.1 & 1.1 \\
\hline A46 & 107 & 137 & 0.56 & 0.4 & 2.1 & 1.9 & -0.13 & 0.13 & -0.64 & -0.65 & 1.2 & 1.1 \\
\hline A47 & 107 & 137 & 0.45 & 0.3 & 2.0 & 1.7 & 0.04 & 0.27 & -0.87 & -0.72 & 1.2 & 1.2 \\
\hline A48 & 107 & 136 & 0.40 & 0.3 & 1.1 & 1.1 & 0.76 & 0.91 & -0.35 & 0.25 & 1.2 & 1.1 \\
\hline A49 & 105 & 136 & 0.40 & 0.37 & 2.8 & 2.7 & -0.64 & -0.66 & -0.37 & -0.22 & 1.1 & 1.1 \\
\hline RA28 & 107 & 136 & 0.02 & 0.02 & 2.7 & 2.8 & -0.65 & -0.64 & -0.88 & -0.67 & 1.4 & 1.2 \\
\hline RA38 & 106 & 137 & -0.16 & -0.01 & 3.0 & 2.8 & -1.02 & -0.52 & 0.75 & -0.69 & 1.1 & 1.1 \\
\hline RA6 & 106 & 137 & 0.08 & -0.06 & 3.1 & 2.7 & -0.96 & -0.50 & 0.29 & -0.49 & 1.1 & 1.2 \\
\hline RA23 & 107 & 137 & -0.28 & -0.09 & 2.4 & 2.2 & -0.33 & -0.07 & -0.42 & -0.59 & 1.1 & 1.1 \\
\hline $\mathrm{R} \quad \mathrm{A} /$ & & 137 & & & & & & & & & & \\
\hline A35 & 107 & & 0.03 & 0.41 & 2.4 & 2.1 & -0.39 & 0.26 & -0.59 & -0.15 & 1.2 & 1.0 \\
\hline
\end{tabular}

I - initial sample; II - comparison sample; Letter R before an item indicates n-sample size; r.drop - Item whole correlation for this item against the scale without this item; sd - the standard deviation of each item.

Additional statistics and content of items are available on request by e-mail: emils.kalis@gmail.com 